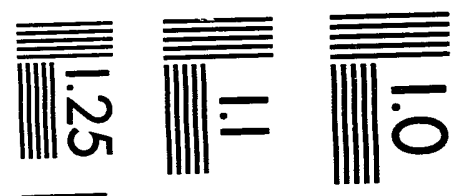

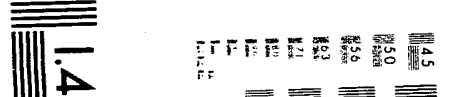

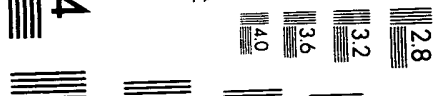

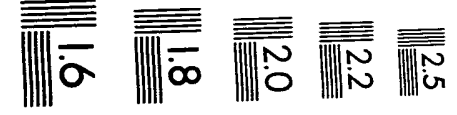



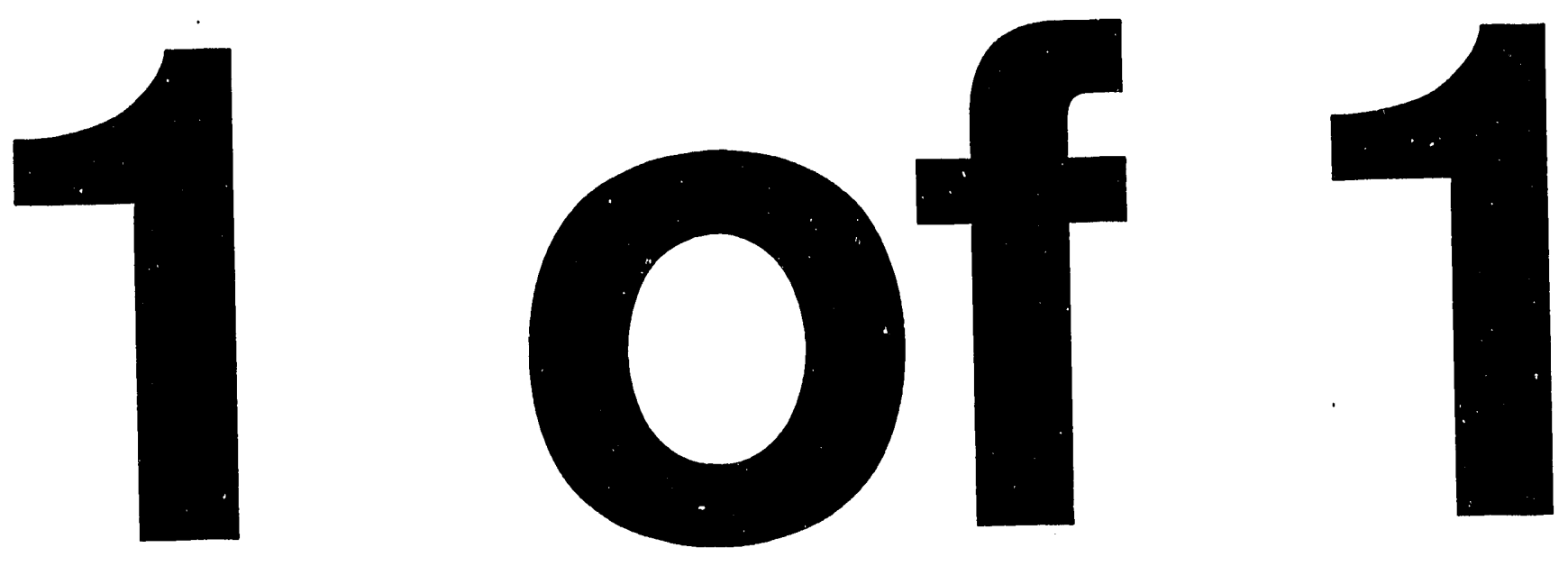


$$
\cos 1-9308158--3
$$

UCRL-JC- 114192

PREPRINT

\title{
CARBON AEROGELS: AN UPDATE ON STRUCTURE, PROPERTIES, AND APPLICATIONS
}

\author{
R. W. Pekala \\ S. T. Mayer \\ J. L. Kaschmitter \\ F.M. Kong
}

This paper was prepared for submittal to International Symposium on Advances in

Sol-Gel Processing and Applications

Chicago, Illinois

August 24-28, 1993

July 1993

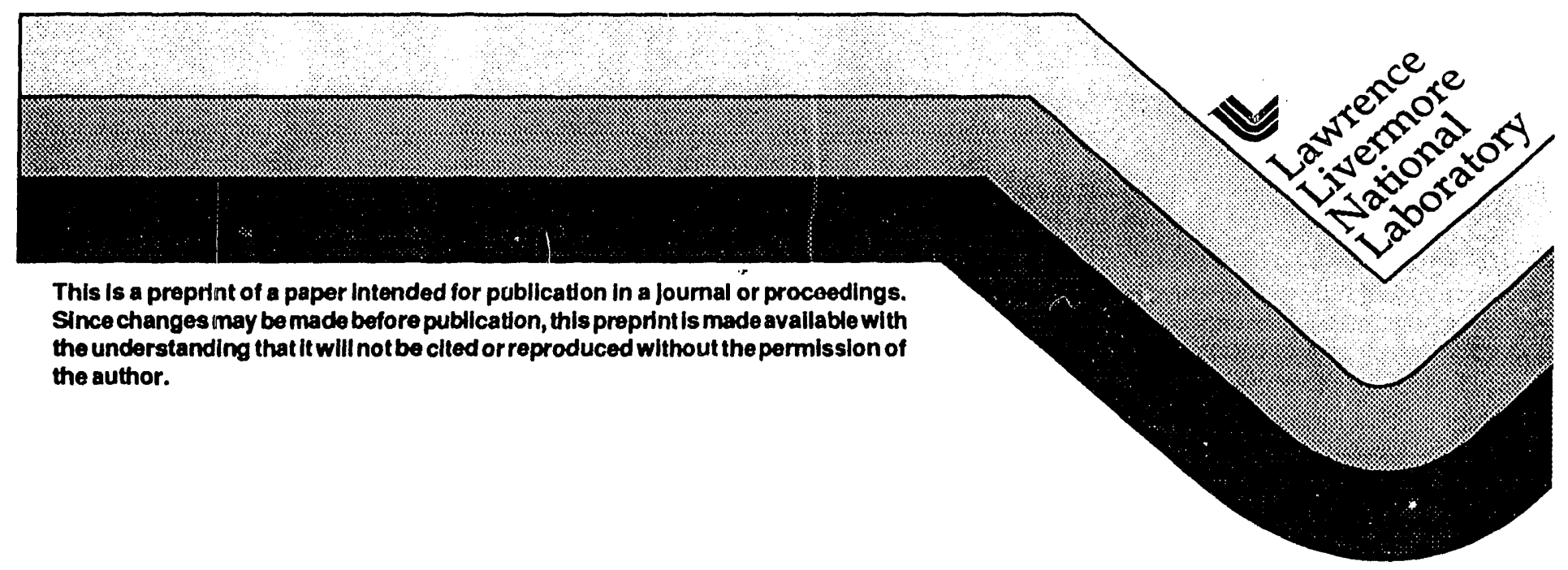




\section{DISCLAIMER}

This document was prepared as an account of work sponsored by an agency of the United States Govermment. Neither the United Stales Government nor the University of California nor any of their employees, makes any warranty, express or implied, or assumes any legal liability or responsibility for the accu racy, completeness, or usefulness of any information, apparatus, produch, or process disclosed, or represents that its use would not infringe privately owned rights. Reference herein to any specific commercial products, process, or service by trade name, trademark, manufacturer, or otherwise, does not necessarily constitute or imply its endorsement, recommendation, or favoring by the United States Govemment or the University of California. The views and opinions of authors expressed herein do not mecessarily state or reflect those of the Uniled States Government or the University of Califomia, and shall not be used for advertising or product endorsement purposes. 


\title{
CARBON AEROGELS: AN UPDATE ON STRUCTURE, PROPERTIES, AND APPLICATIONS
}

R.W. Pekala, S.T. Mayer, J.L. Kaschmitter*, and F.M. Kong

Chemistry \& Materials Science Department

*Electrical Engineering Department

Lawrence Livermore National Laboratory

Livermore, CA 94550

\begin{abstract}
Aerogels are unique porous materials whose composition, structure, and properties can be controlled at the nanometer scale. This paper examines the synthesis of organic aerogels and their carbonized derivatives. Carbon aerogels have low electrical resistivity, high surface area, and a tunable pore size. These materials are finding applications as electrodes in double layer capacitors.
\end{abstract}




\section{INTRODUCTION}

Although Kistler demonstrated the supercritical drying of organic gels in the 1950s, the resultant materials would not be considered aerogels by today's standards [1-2]. Aerogels are porous materials in which all structural entities (i.e., cells, pores, particles) are smaller than $100 \mathrm{~nm}$. Kistler noted that his cellulose. nitrocelluk se, geiatin, agar, and egg albumin foams were white, implying that they had cell sizes sufficienily large to scatter light $(>100 \mathrm{~nm})$. Recently, we showed that certain organic reactions proceed through sol-gel transitions. The resultant crosslinked gels can be supercritically dried to form aerogels. Thermal, acoustic, optical, and mechanical property measurements show that these organic aerogels are similar to their inorganic counterparts [3-5].

Aerogels resulting from the reaction of (1) resorcinol with formaldehyde and (2) -melamine with formaldehyde have been studied in great detail [6-8]. The former materials have also been pyrolyzed in an inert atmosphere to form carbon aerogels [9]. This paper describes new methods for forming organic aerogels into thin films and microspheres. The effects of polymerization conditions, pyrolysis temperature, and activation procedures on the structure and properties of carbon aerogels are discussed. Finally, the use of carbon aerogels in double layer capacitors is described.

\section{AEROGEL PREPARATION}

The preparation of resorcinol-formaldehyde (RF) gels involves mixing the reactants in a 1:2 molar ratio, respectively. Deionized and distilled water is added as the diluent and sodium carbonate as the base catalyst. After stirring to form a homogeneous solution, the mixture is poured into glass vials, sealed, and cured at elevated temperature. For solutions containing $\leq 10 \% \mathrm{w} / \mathrm{v}$ reactants, the sol-gel polymerization is carried out at 85 $95^{\circ} \mathrm{C}$ for 7 days. At higher reactant concentrations, the solution is cured for 1 day at room temperature, followed by 1 day at $50^{\circ} \mathrm{C}$ and 3 days at $85-95^{\circ} \mathrm{C}$. Upon completion of the cure cycle, the crosslinked gels are removed from their glass vials, and the pore fluid (i.e., water) is exchanged with acetone. The acetone-filled gels are then placed in a jacketed pressure vessel, exchanged with liquid carbon dioxide, and supercrtically dried $\left(\mathrm{T}_{\mathrm{c}}=31^{\circ} \mathrm{C} ; \mathrm{P}_{\mathrm{c}}=7.4 \mathrm{MPa}\right)$. This procedure has resulted in the production of monolithic $\mathrm{RF}$ aerogels in cylindrical form ( $25 \mathrm{~mm}$ diameter $x 60-85 \mathrm{~mm}$ long). These materials are subsequently pyrolyzed in an inert atmosphere to form carbon aerogels.

$\mathrm{RF}$ and carbon aerogels can also be produced in the form of thin films or spherical particles. The thin films are formed by casting the RF solution between flat glass plates $(30 \mathrm{~cm} \mathrm{X} 30 \mathrm{~cm})$ with a polymer spacer (e.g., cellulose acetate) around the edges. After curing, the film can be cut into any desired shape and processed. This procedure has been used to produce carbon aerogel electrodes (35 mm diameter; $100-500 \mu \mathrm{m}$ thick) for double layer capacitors.

An inverse emulsion polymerization is used to produce aerogel particles that we refer to as microspheres. In a glass reaction kettle, 1 liter of cyclohexane or mineral oil is heated to $50-70^{\circ} \mathrm{C}$. In a separate beaker, an $\mathrm{RF}$ solution is partially polymerized until it is approaching the gel point. Approximately $150 \mathrm{ml}$ of the RF solution is added slowly to the cyclohexane with agitation. The RF solution is dispersed into spherical droplets throughout the cyclohexane --- their size depending upon the agitation rate and the presence or absence of surfactant. After the inverse emulsion has been heated for 2-8 hours, the agitation is stopped and the spherical gel particles are allowed to settle. The cyclohexane is decanted from the reaction kettle and replaced with acetone. The solution is agitated to assist in the solvent exchange of acetone for water inside the gel particles. 
After sufficient solvent exchanges, the gel particles are supercritically dried from carbon dioxide. The resultant microspheres can range in size from microns to millimeters depending upon the emulsification procedure. RF, carbon, and melamine-formaldehyde (MF) microspheres have been synthesized.

\section{STRUCTURE AND PROPERTIES}

While monolithic aerogels are ideal candidates for many applications (e.g., transparent window insulation), the large and expensive processing equipment necessary for the production of reasonably sized aerogels has limited the commercial application of this extraordinary material. The formation of aerogel microspheres offers an attractive alternative to monolith production. The aerogel microspheres can be produced in a semicontinuous process, and they can be used as additives in conventional foaming operations to produce new composites foams with superior acoustic and thermal properties. Silica microspheres have been produced and their thermal performance has been characterized [10-12]. RF and MF microspheres should have even better thermal properties because of the lower solid conductivity of these polymer matrices as compared to silica.

Figure 1 shows an optical micrograph of RF and carbon microspheres. A relatively broar. size distribution is observed in each case, with the RF spheres averaging 40-50 $\mu$ in diameter. The carbon microspheres are smaller than their RF precursors as a result of shrinkage during pyrolysis. Figure 2 shows a scanning electron micrograph of a different batch of carbon microspheres. Although the aerogel structure within the microspheres cannot be delineated, it is clear that the particles are quite spherical with smooth surfaces.

The structure and properties of carbon aerogels are largely controlled by three factors: (1) the [Resorcinol]/[Catalyst] (R/C) ratio of the starting solution, (2) the pyrolysis temperature, and (3) chemical activation procedures. The $\mathrm{R} / \mathrm{C}$ ratio affects the number of RF clusters generated in solution and the size to which they grow. The particle size, surface area, and interconnectivity of both RF and carbon aerogels strongly depend on this parameter. Figure 3 shows that the specific surface area of carbon aerogels is practically independent of the bulk density for samples prepared at the same $\mathrm{R} / \mathrm{C}$ ratio. These data are corroborated by transmission electron micrographs that show interconnected particles of approximately the same size. Thus, carbon aerogels with a higher bulk density simply have more interconnected particles per unit volume than their low density counterparts.

In general, most phenolic-like resins do not completely graphitize even upon heating above $2500^{\circ} \mathrm{C}$. Resorcinol-formaldehyde aerogels pyrolyzed at $1050^{\circ} \mathrm{C}$ in an inert atmosphere are converted into a nanocrystalline carbon structure. Helium pycnometry reveals a skeletal density of $2.06 \mathrm{~g} / \mathrm{cm}^{3}$ which is much higher than most conventional glassy carbons $\left(\sim 1.5 \mathrm{~g} / \mathrm{cm}^{3}\right)$ [13]. These data imply that carbon aerogels have very few closed pores within the solid skeleton. Raman data reveal an in-plane microcrystallite size $\left(\mathrm{L}_{\mathrm{a}}\right)$ of $\sim 25 \AA$ for carbon aerogels $\left(\mathrm{R} / \mathrm{C}=200 ; 1050^{\circ} \mathrm{C}\right)$ independent of the bulk density. Even samples pyrolyzed at $2100^{\circ} \mathrm{C}$ reveal a large disorder-induced Raman line, with the microcrystallite size only growing to $\sim 40 \AA$ [14]. Thus, the picture that emerges for carbon aerogels is one in which $25-40 \AA$ wide graphene sheets intertwine to make up the individual $\sim 120 \AA$ diameter particles.

Carbon aerogels pyrolyzed at 4 different temperatures were examined by high resolution electron microscopy (JEOL JEM $4000 \mathrm{EX}$ at $400 \mathrm{kVaccelerating} \mathrm{voltage).} \mathrm{In} \mathrm{general,} \mathrm{the}$ microstructure resembles that of turbostratic carbon where the basal planes are aligned 
parallel to the electron beam and appear as nearly straight lines in the images. The local ordering within the aerogels becomes apparemt with the increased annealing temperature. Figures $4 \mathrm{a} \& 4 \mathrm{~b}$ reveals the local structure of carbon aerogels pyrolyzed at 1050,1500 , 1800 , and $2100^{\circ} \mathrm{C}$. An interconnected particle structure is seen in all cases. At $1050^{\circ} \mathrm{C}$, the structure is largely amorphous with the appearance of short lattice fringes in the neck region between particles (see arrows A). At $1500^{\circ} \mathrm{C}$, longer and more continuous lattice fringes are observed in the neck region (see arrow B1) and around the circumference of the spherical particles (see arrow B2). At $1800^{\circ} \mathrm{C}$, chains in the neck region disappear and become integrated into the individual particles. The basal planes are loosely wrapped around the circumference of the particles (see arrow $\mathrm{C}$ ), and they do not overlap or tangle as much as the lower temperature samples. There is distinctively more order at $180{ }^{\circ} \mathrm{C}$ with 4-5 layers of aligned planes being traceable over long distances. At $2100^{\circ} \mathrm{C}$, the ordering within the particles is readily apparent where up to 10 lattice planes can be seen in parallel. The lattice planes follow the circumference of the individual particles, where each plane can be observed to bend at the same radius thus faceting the bead into crystallographic shapes (arrow D). The distance between lattice planes was $\sim 4.04 \AA$.

The final method for modifying the carbon aerogel structure involves chemical activation. In the carbon industry, activation is commonly achieved by exposing carbon particles or fibers to an oxidizing atmosphere such as steam, air, or carbon dioxide at $750-1000^{\circ} \mathrm{C}$ $[15,16]$. This procedure usually results in high surface areas $\left(>1000 \mathrm{~m}^{2} / \mathrm{g}\right)$. A different type of chemical activation can be achieved when carbon is heated in concentrated acids [17]. We have modified carbon aerogels using each of these procedures. Carbon aerogels synthesized at $\mathrm{R} / \mathrm{C}=50$ and $\mathrm{R} / \mathrm{C}=200$ were pyrolyzed under nitrogen until reaching $1050^{\circ} \mathrm{C}$, at which time the purge gas was switched to carbon dioxide for 3 hours. Next, the tube furnace was switched to nitrogen as it cooled under its own thermal mass. Table I shows the effects of the $\mathrm{CO}_{2}$ activation. $\mathrm{A} \sim 2 \mathrm{X}$ increase in the BET surface area was observed for each sample. If the samples are treated for $>3$ hours with $\mathrm{CO}_{2}$, they begin to lose their structural integrity.

In the case of the nitric acid treatment, the BET surface area decreases slightly $(<15 \%)$, and the pore size distribution shifts to a larger value with a broader distribution. Figure 5 compares the mesopore size distribution for $\mathrm{HNO}_{3}$-treated and untreated carbon aerogels. Effects upon the micropore size are under investigation.

\section{APPLICATIONS}

Carbon aerogels are the first electrically conductive aerogels to be synthesized. Furthermore, these materials are quite pure as compared to other forms of carbon powders or fibers (i.e., they have little inorganic ash content). These attributes have led us to investigate thin film carbon aerogels as electrodes in double layer capacitors. These devices store charge at a polarized solid/electrolyte interface, resulting in the storage of energy in the space charge region. This phenomenon is driven by the available surface area of the electrode material and the proper pore size distribution. Carbon aerogels provide an almost ideal electrode material because of their low electrical resistivity $(<40$ mohm-cm), controllable pore size distribution (5-500 $\AA$ ), and high volumetric surface areas $\left(\sim 500 \mathrm{~m}^{2} / \mathrm{cm}^{3}\right)$.

The exceptionally high conductivity of carbon aerogels, in contrast to loosely bonded carbon powders or activated carbon fiber clothes (ACFCs), is attributable to its monolithic structure which is composed of covalently-bonded carbon particles. Electrical conduction takes place by both the drift of delocalized charge carriers within the carbon 
particles and the transfer of carriers from one large conducting segment to another by hopping or tunneling $[18,19]$. In contrast to electrodes made from compacted carbon powders, the activation energy fo: transport between carbon particles is relatively small in the carbon aerogels, resulting in supercapacitors with potentially high power densities.

In combination with their high specific surface areas, carbon aerogels can be produced with densities ranging from $0.05-1.0 \mathrm{~g} / \mathrm{cm}^{3}$. As a result, volumetric surface areas of greater than $500 \mathrm{~m}^{2} / \mathrm{cm}^{3}$ can be achieved. In contrast, ACFCs have higher specific areas $\left(\sim 2000 \mathrm{~m}^{2} / \mathrm{g}\right)$ but lower bulk densities $\left(0.1 \mathrm{~g} / \mathrm{cm}^{3}\right)$, resulting in volumetric surface areas of only $200 \mathrm{~m}^{2} / \mathrm{cm}^{3}[20,21]$. This parameter is the key to high energy density supercapacitors and provides the rationale for pursuing carbon aerogels as an advanced electrode material.

Figure 6 shows a schematic diagram of the Aerocapacitor (i.e., a double layer capacitor that utilizes carbon aerogel electrodes). The carbon aerogels serve as both the positive and negative electrodes, with a porous suparator in-between. The separator (e.g., polypropylene membrane) is electrically isolating but ionically conductive. The void space in both the separator and aerogels is filled with an electrolyte such as $\mathrm{KOH}$. The applied voltage cause a migration of the potassium cations and hydroxyl anions to the oppositely charged aerogel electrode. The energy is effectively stored in the $\sim 5 \AA$ double layer at the aerogel/electrolyte interface.

Figure 7 shows the capacitance $\left(\mathrm{F} / \mathrm{cm}^{3}\right)$ as a function of the aerogel density for several $\mathrm{R} / \mathrm{C}$ formulations [22]. In general, the capacitance increases with bulk density until a plateau region is reached at $\sim 0.7 \mathrm{~g} / \mathrm{cm}^{3}$. A maximum capacitance density of $\sim 26 \mathrm{~F} / \mathrm{cm}^{3}$ is achieved for untreated aerogels. If the carbon aerogel structure is modified with a $\mathrm{HNO}_{3}$ treatment, the capacitance density increases to $\sim 35 \mathrm{~F} / \mathrm{cm}^{3}$. While our data show a small decrease in the specific surface area of $\mathrm{HNO}_{3}$-treated carbon aerogels, we believe that a modification of the pore size distribution results in higher accessible !urface area. Furthermore, the introduction of carboxyl groups at the surface of the carbon particles may affect the electric double layer. Preliminary tests on $\mathrm{CO}_{2}$-activated carbon aerogels show a $\sim 66 \%$ increase in capacitance as compared to control specimens, but values in excess of $\sim 26 \mathrm{~F} / \mathrm{cm}^{3}$ have not yet been achieved. Future research is being directed at maximizing capacitance in thin film carbon aerogels.

\section{SUMMARY}

Organic aerogels can be produced as monoliths, thin films, or microspheres. A major advantage of these materials is their low $\mathrm{Z}$ (atomic number) composition. Carbon aerogels are of particular importance because they are the first electrically conductive aerogels to be synthesized. Polymerization conditions, pyrolysis temperature, and activation procedure are the major variables that control the structure and properties of carbon aerogels at the nanometer scale. These aerogels are being investigated as electrodes in double layer capacitors. Initial test results show capacitances as high as 35 $\mathrm{F} / \mathrm{cm}^{3}$.

\section{ACKNOWLEDGMENTS}

This work was performed under the auspices of the U.S. Department of Energy by Lawrence Livermore National Laboratory under contract \#W-7405-ENG-48. The authors would like to thank (1) Dr. Peggy Olsen for providing the high resolution TEM photos, 
(2) Suzy Hulsey for the surface area and pore size measurements, (3) Cindy Alviso for the production of aerogel microspheres, (4) Eleno Mones for the fabrication of aerogel thin films, and (5) Ben Mendoza for the $\mathrm{CO}_{2}$-activation experiments.

\section{REFERENCES}

[1] S.S. Kistler, Nature, 127, 741 (1931).

[2] S.S. Kistler, J. Phys. Chem., 36, 52 (1932).

[3] R.W. Pekala, C.T. Alviso, and J.D. LeMay, J. Non-Cryst. Solids, 125, 67 (1990).

[4] X. Lu, M.C. Arduini-Schuster, J. Kuhn, O. Nilsson, J. Fricke, and R.W. Pekala, Science, 255, 971 (1992).

[5] J. Gross, J. Fricke, R.W. Pekala, and L.W. Hrubesh, Phys. Rev. B, 45(22), 12774 (1992).

[6] R.W. Pekala, C.T. Alviso, and J.D. LeMay, in Chemical Processing of Advanced Materials, L.L. Hench and J.K. West, eds., (New York: John Wiley \& Sons, Inc., 1992), pp. 671-683.

[7] R.W. Pekala, C.T. Alviso, F.M. Kong, and S.S. Hulsey, J. Non-Cryst. Solids, 145 , 90 (1992).

[8] R.W. Pekala and F.M. Kong, J. Physics (Fr.), Coll. Suppl. 50(4), C4-33, (1989).

[9] R.W. Pekala and C.T. Alviso, in Novel Forms of Carbon, C.L. Renschler, J.J. Pouch, and D.M Cox, eds., MRS Symp. Proc. 270, 3 (1992).

[10] D.Buttner, E. Hummer, and J. Fricke, in Aerogels, J. Fricke, ed., (New York: Springer-Verlag, 1986), pp. 116-120.

[11] W. Platzer, V. Wittwer, and M. Mielke, in Aerogels, J. Fricke, ed., (New York: Springer-Verlag, 1986), pp. 127-132.

[12] F.J. Broecker, W. Heckmann, F. Fischer, M. Mielke, J. Schroeder, and A. Stange, in Aerogels, J. Fricke, ed., (New York: Springer-Verlag, 1986), pp. 160-166.

[13] G.M. Jenkins and K. Kawamura, Polymeric carbons - carbon fibre, glass and char, (New York: Cambridge Univ. Press, 1976), p. 110.

[14] Prof. Millie Dresselhaus, MIT, private communication.

[15] H. Jarikowska, A. Swiatkowski, and J. Choma, Active Carbon, (New York: Ellis Horwood, 1991), pp. 38-52.

[16] K. Kinoshita, Carbon, (New York: John Wiley \& Sons, 1988).

[17] Y. Otake and R.G. Jenkins, Carbon, 31(1), 109 (1993).

[18] A.W.P. Fung, Z.H. Wang, K. Lu, M.S. Dresselhaus, and R.W. Pekala, J. Mat. Res., in press.

[19] X. Lu, O. Nilsson, J. Fricke, and R.W. Pekala, J. Appl. Phys., 73(2), 581 (1993).

[20] I. Tanahashi, A. Yoshida, and A. Nishino, Carbon, 28(4), 477 (1990).

[21] I. Tanahashi, A. Yoshida, and A. Nishino, J. Electochem. Soc., 137(10), 3052 (1990).

[22] S.T. Mayer, R.W. Pekala, and J.L. Kaschmitter, J. Electrochem. Soc., 140(2), 446 (1993). 


\section{FIGURE CAPTIONS}

Figure 1. Optical micrographs of (a) resorcinol-formaldehyde and (b) carbon aerogel microspheres synthesized from an inverse emulsion. The wire in each photo is $35 \mu$ in diameter.

Figure 2. Scanning electron micrographs of carbon aerogel microspheres $(\sim 0.8 \mathrm{~g} / \mathrm{cc}$; $\left.\mathrm{R} / \mathrm{C}=200 ; 1050^{\circ} \mathrm{C}\right)$.

Figure 3. Specific surface area of carbon aerogels vs. bulk density. All samples were synthesized at $\mathrm{R} / \mathrm{C}=200$ and pyrolyzed at $1050^{\circ} \mathrm{C}$ in a nitrogen atmosphere.

Figure 4(a). High resolution transmission electron micrographs of carbon aerogels pyrolyzed at $1050^{\circ} \mathrm{C}$ and $1500^{\circ} \mathrm{C}$ in an inert atmosphere.

Figure 4(b) High resolution transmission electron micrographs of carbon aerogels pyrolyzed at $1800^{\circ} \mathrm{C}$ and $2100^{\circ} \mathrm{C}$ in an inert atmosphere.

Figure 5. A comparison of the mesopore size distribution of $\mathrm{HNO}_{3}$-treated and untreated carbon aerogels. The $\mathrm{HNO}_{3}$ treatment consisted of exposing a carbon aerogel to $8 \mathrm{M} \mathrm{HNO}_{3}$ for 2 days at $50^{\circ} \mathrm{C}$. The aerogel was then rinsed with copious amounts of distilled water and dried in a convection oven at $50^{\circ} \mathrm{C}$.

Figure 6. A schematic diagram of the Aerocapacitor.

Figure 7. A plot of capacitance density $\left(\mathrm{F} / \mathrm{cm}^{3}\right)$ vs. aerogel bulk density for electrodes synthesized at various $R / C$ ratios. 


\section{Table I}

\begin{tabular}{|c|c|c|c|c|}
\hline $\begin{array}{l}\text { Aerogel } \\
\text { Formulation }\end{array}$ & $\begin{array}{l}\text { Pyrolysis } \\
\text { Conditions }\end{array}$ & $\begin{array}{l}\text { BET Surface } \\
\text { Area }\left(\mathrm{m}^{2} / \mathrm{g}\right)\end{array}$ & $\begin{array}{l}\text { Total Pore } \\
\text { Volume }(\mathrm{cc} / \mathrm{g})\end{array}$ & $\begin{array}{l}\text { Median Mesopore } \\
\text { Diameter }(\AA)\end{array}$ \\
\hline $\begin{array}{l}40 \% ; R / C=200 \\
40 \% ; R / C=200\end{array}$ & $\begin{array}{l}\mathrm{N}_{2} \\
\mathrm{CO}_{2}\end{array}$ & $\begin{array}{r}659 \\
1225\end{array}$ & $\begin{array}{l}1.39 \\
1.83\end{array}$ & $\begin{array}{l}92.7 \\
92.8\end{array}$ \\
\hline $\begin{array}{l}25 \% ; \mathrm{R} / \mathrm{C}=50 \\
25 \% ; \mathrm{R} / \mathrm{C}=50\end{array}$ & $\begin{array}{l}\mathrm{N}_{2} \\
\mathrm{CO}_{2}\end{array}$ & $\begin{array}{r}776 \\
1321\end{array}$ & $\begin{array}{l}1.28 \\
1.62\end{array}$ & $\begin{array}{l}56.8 \\
57.2\end{array}$ \\
\hline
\end{tabular}

*all samples were pyrolyzed for 3 hours at $1050^{\circ} \mathrm{C}$ 

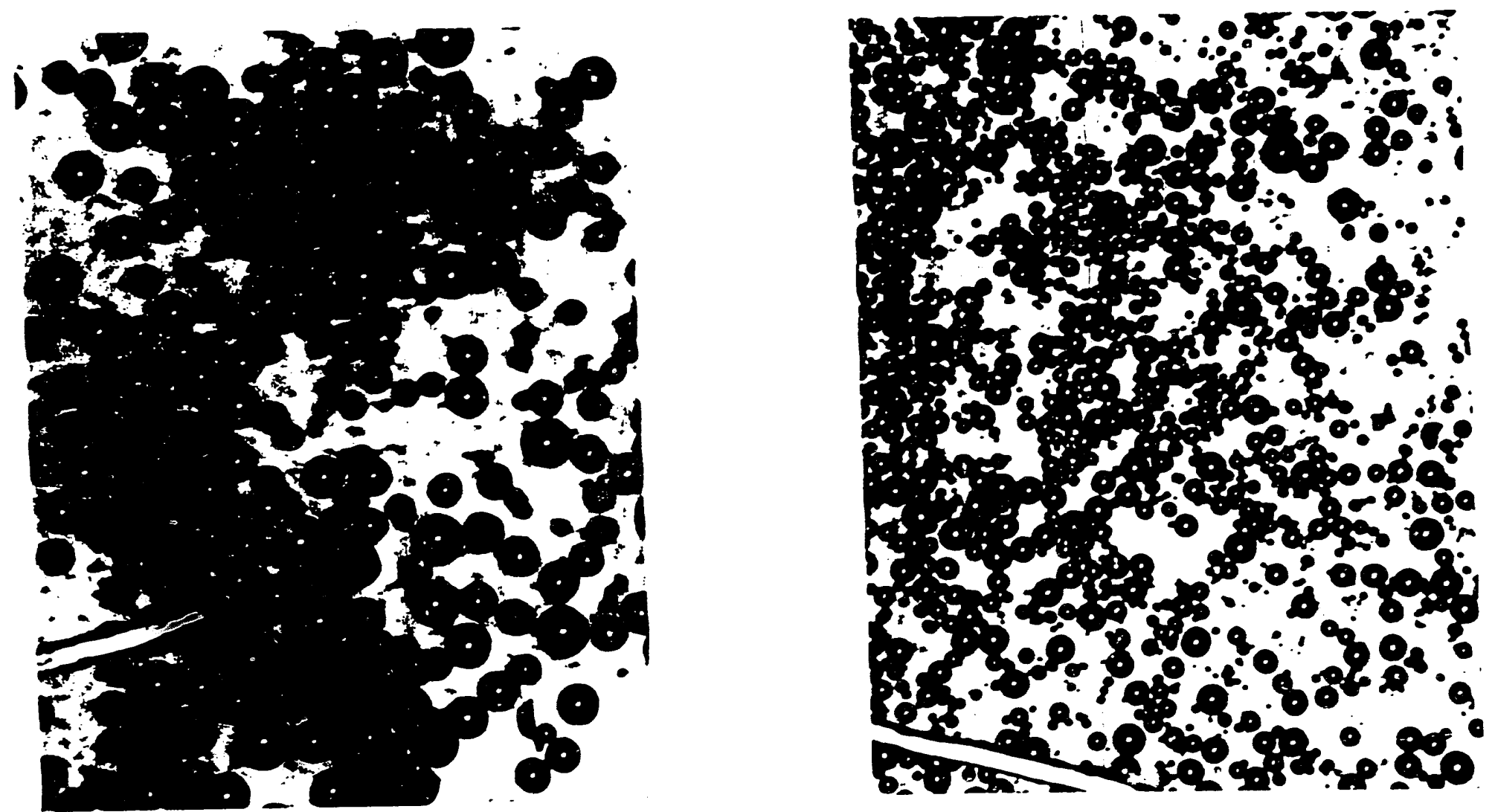

Resorcinol-formaldehyde

Carbon 

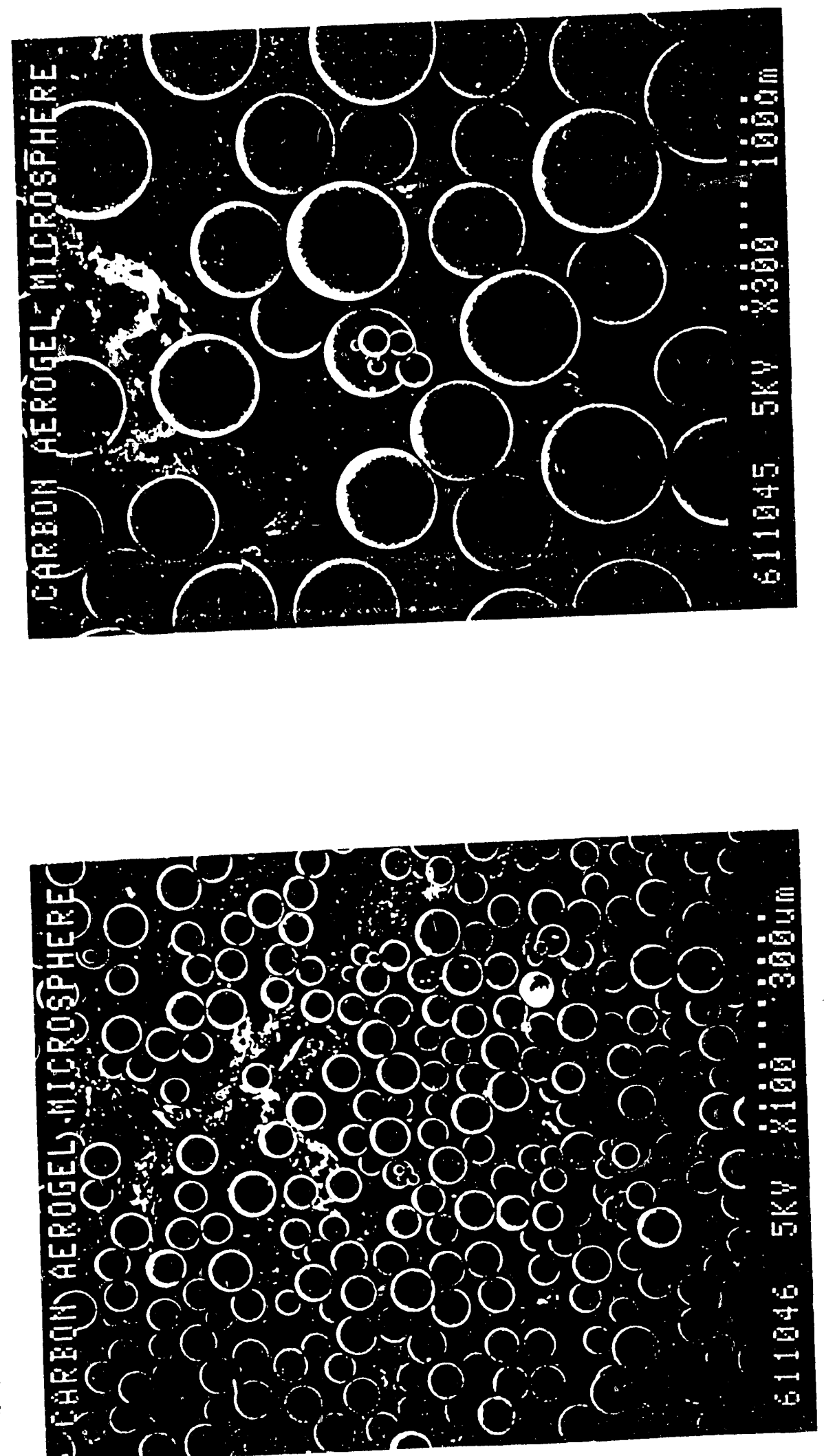
CRF Aerogels $R / C=200$, Pyro $=1050 \mathrm{C}$

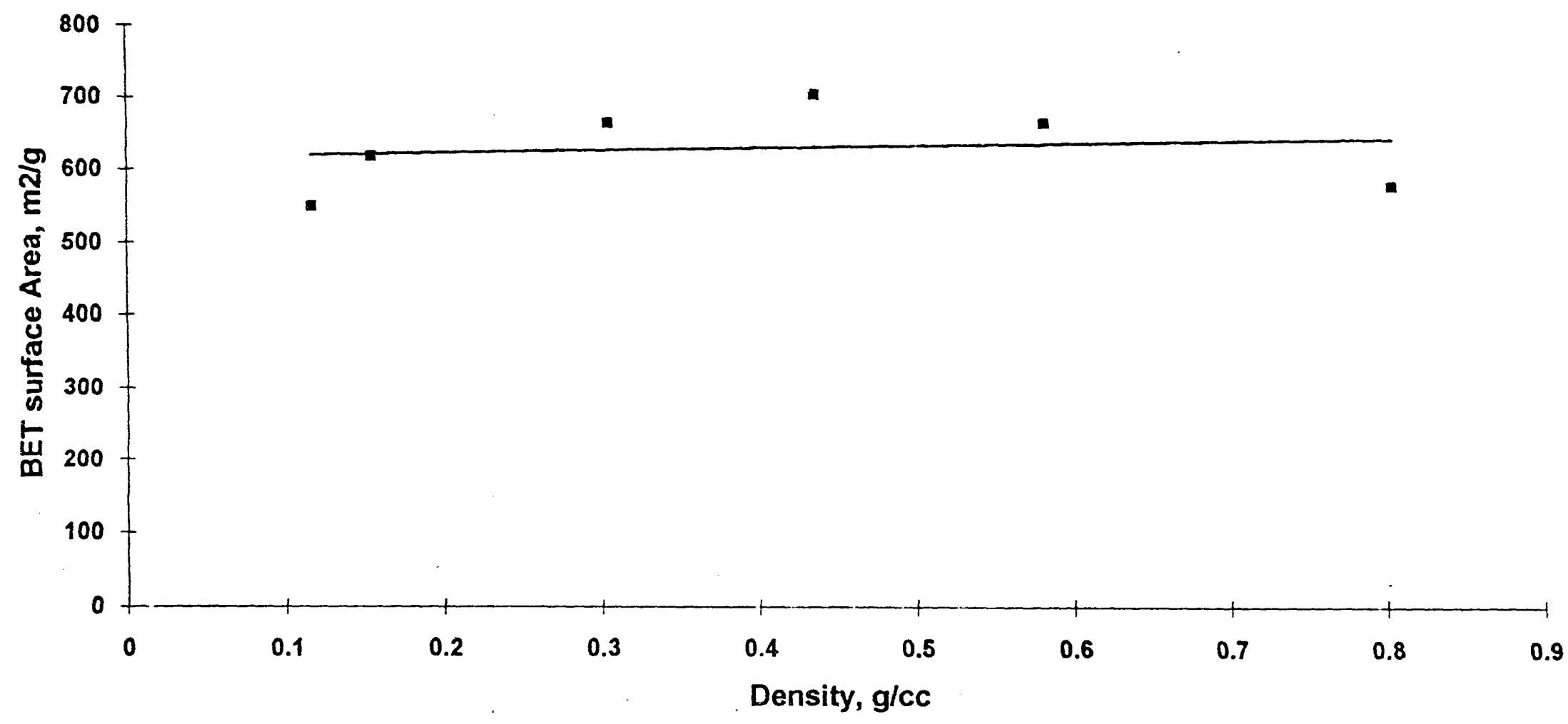

(3) 


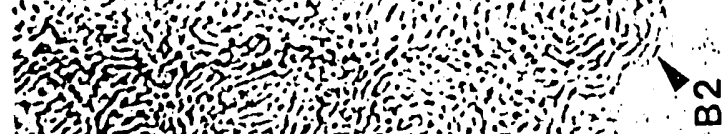

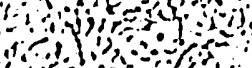

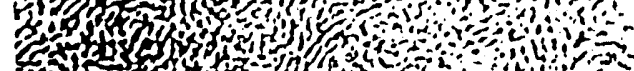

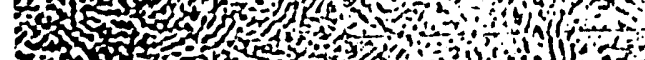
30 (3) W z

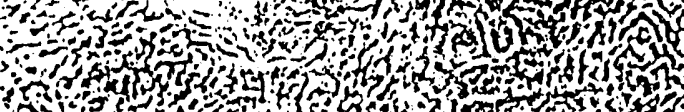

not

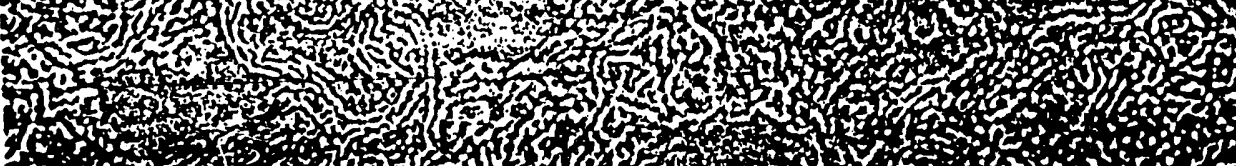

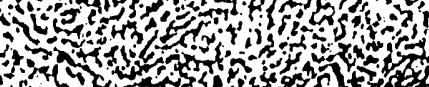

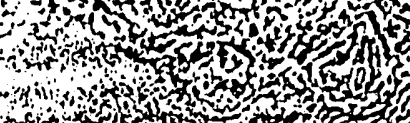

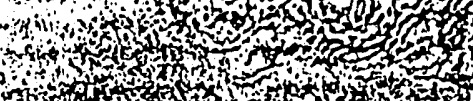

7 .

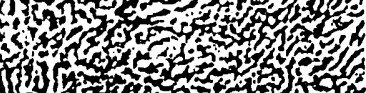

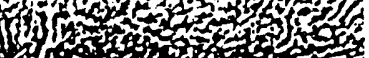

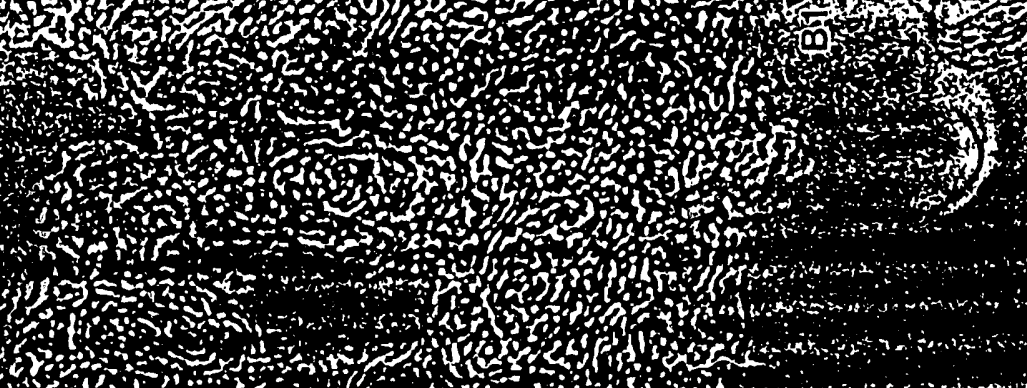

(4)
$+20$

(x)

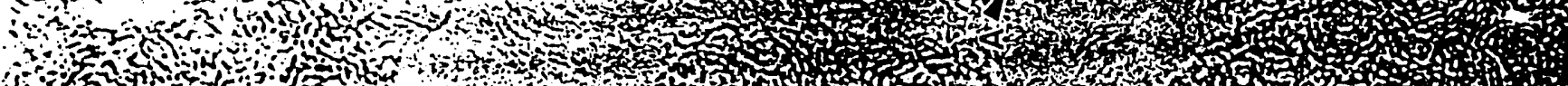

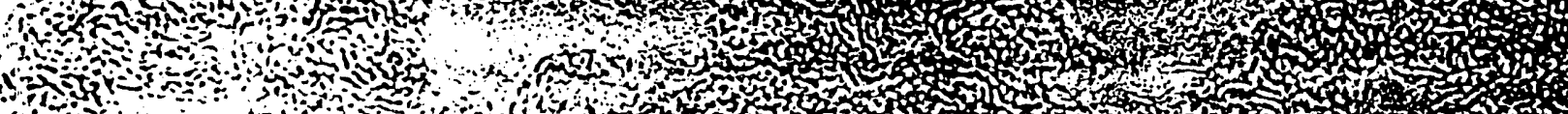

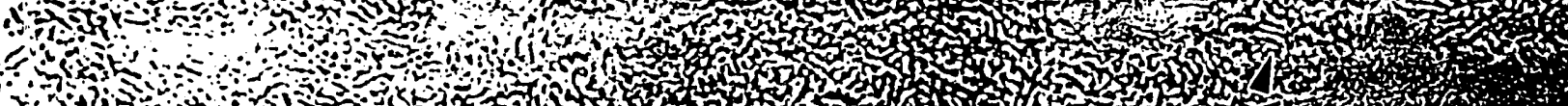

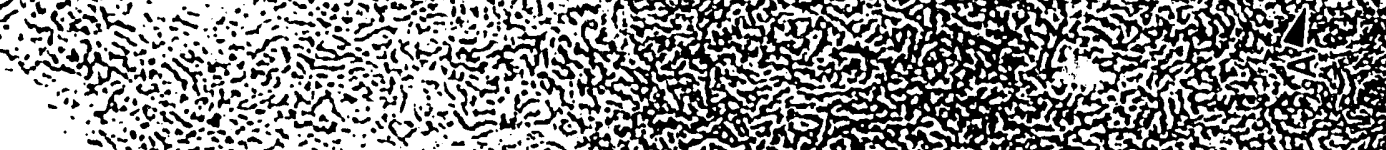

Hof

$$
\text { (1) }
$$


Thanding

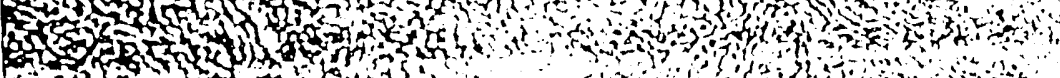

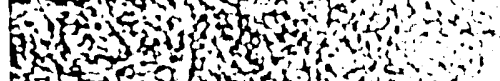

Af

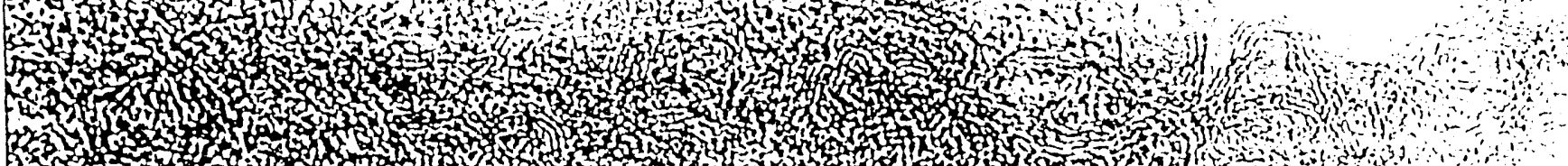

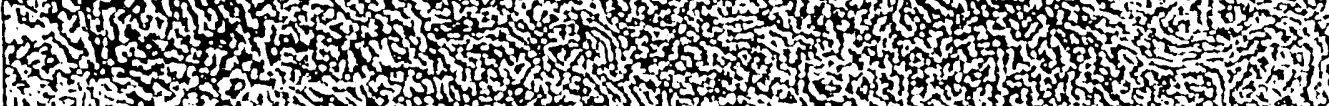

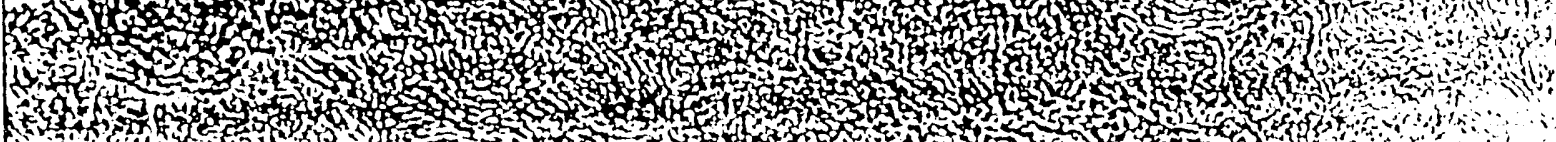

H.

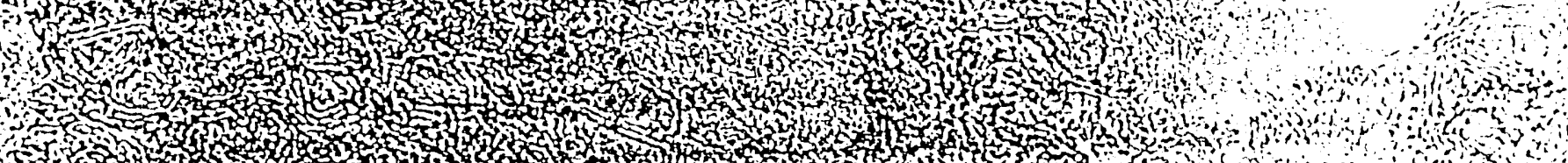

J

P.

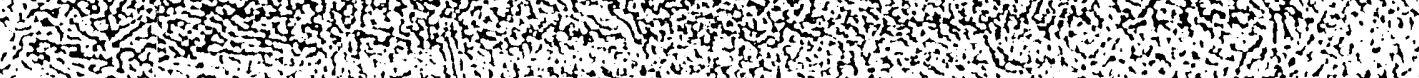

and

$$
\text { ond }
$$
(Fynd G. Find

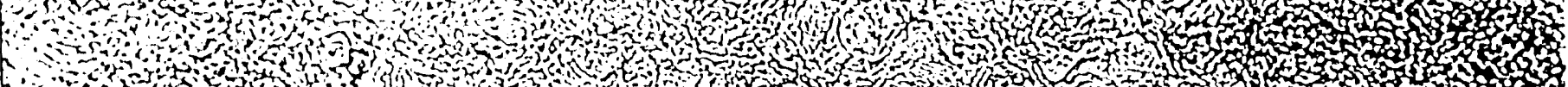
-

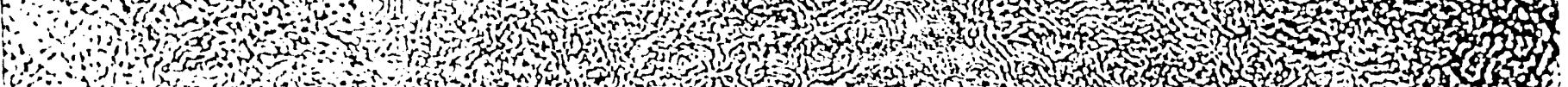
fon (1) Bo

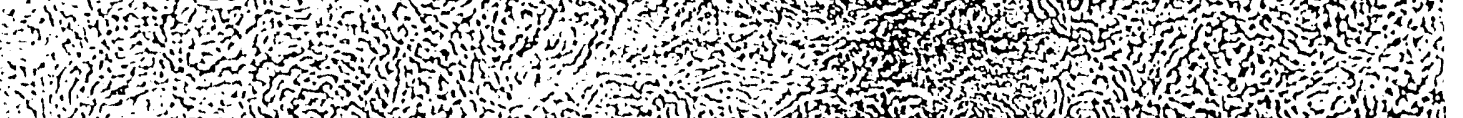

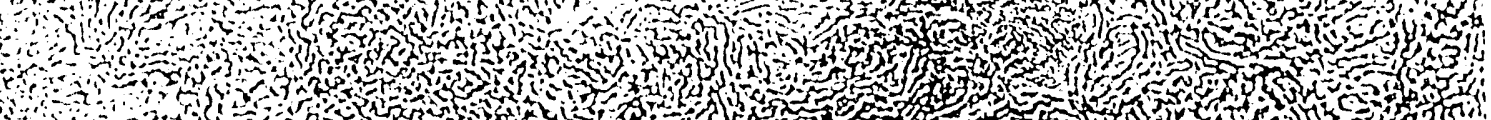

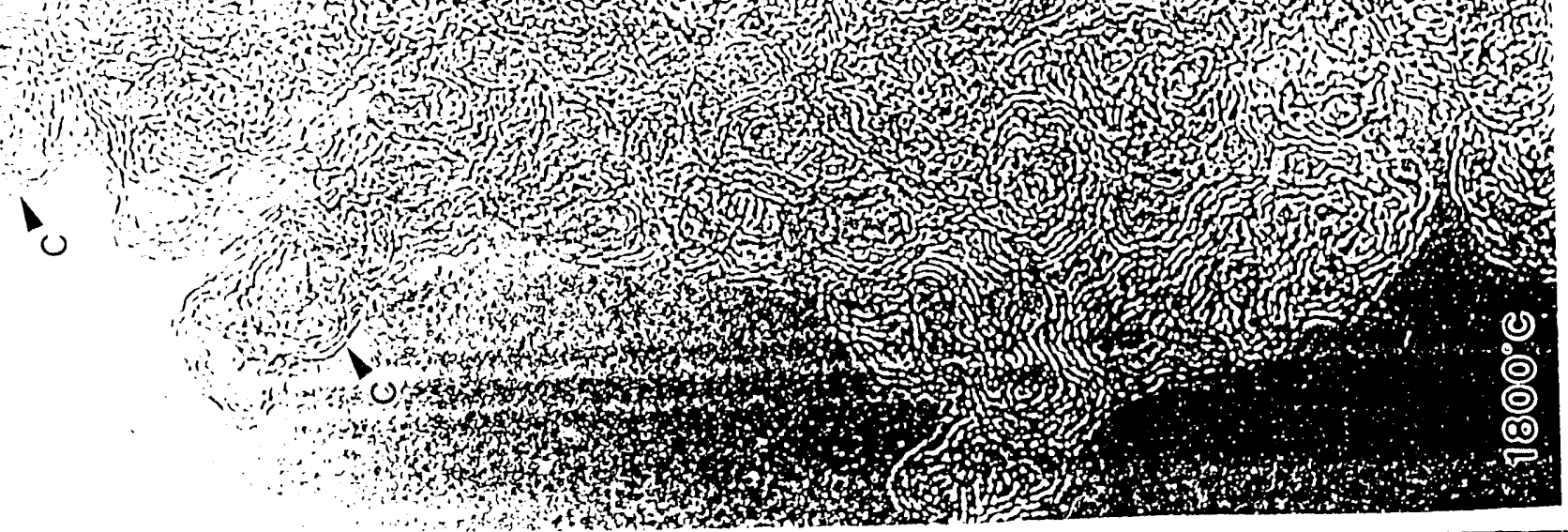


CRF Aerogels R500, R/C=200, Mesopore Distribution

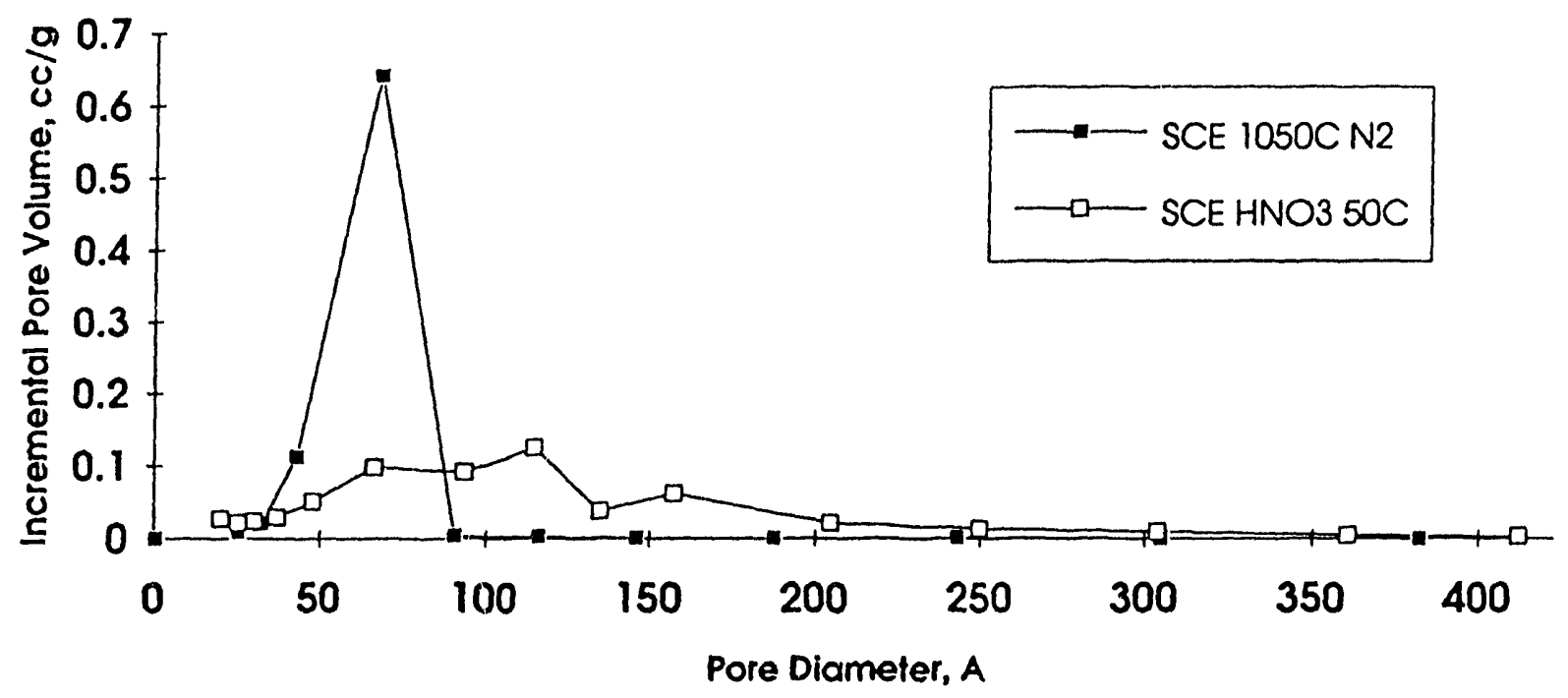




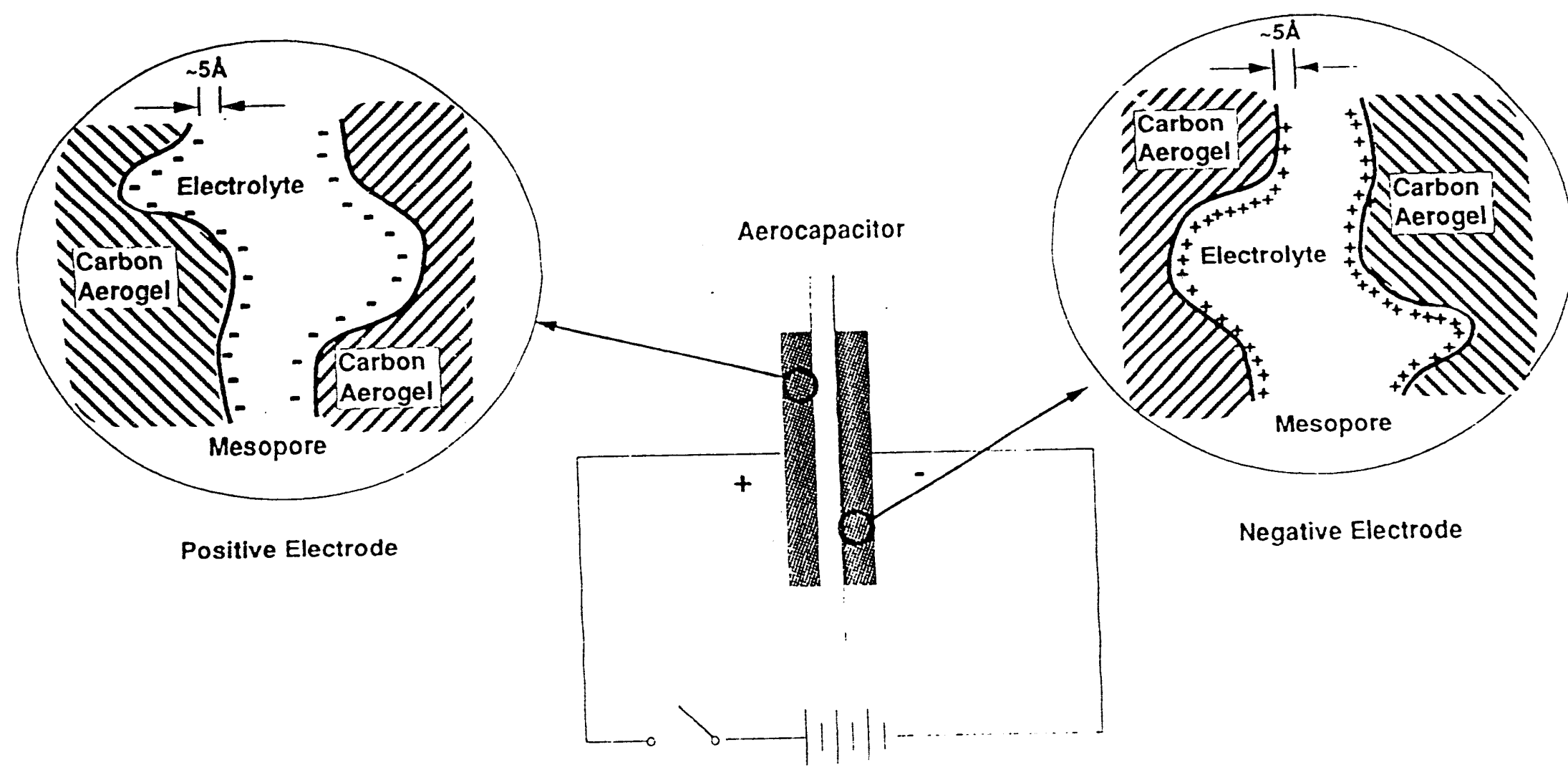

(6) 


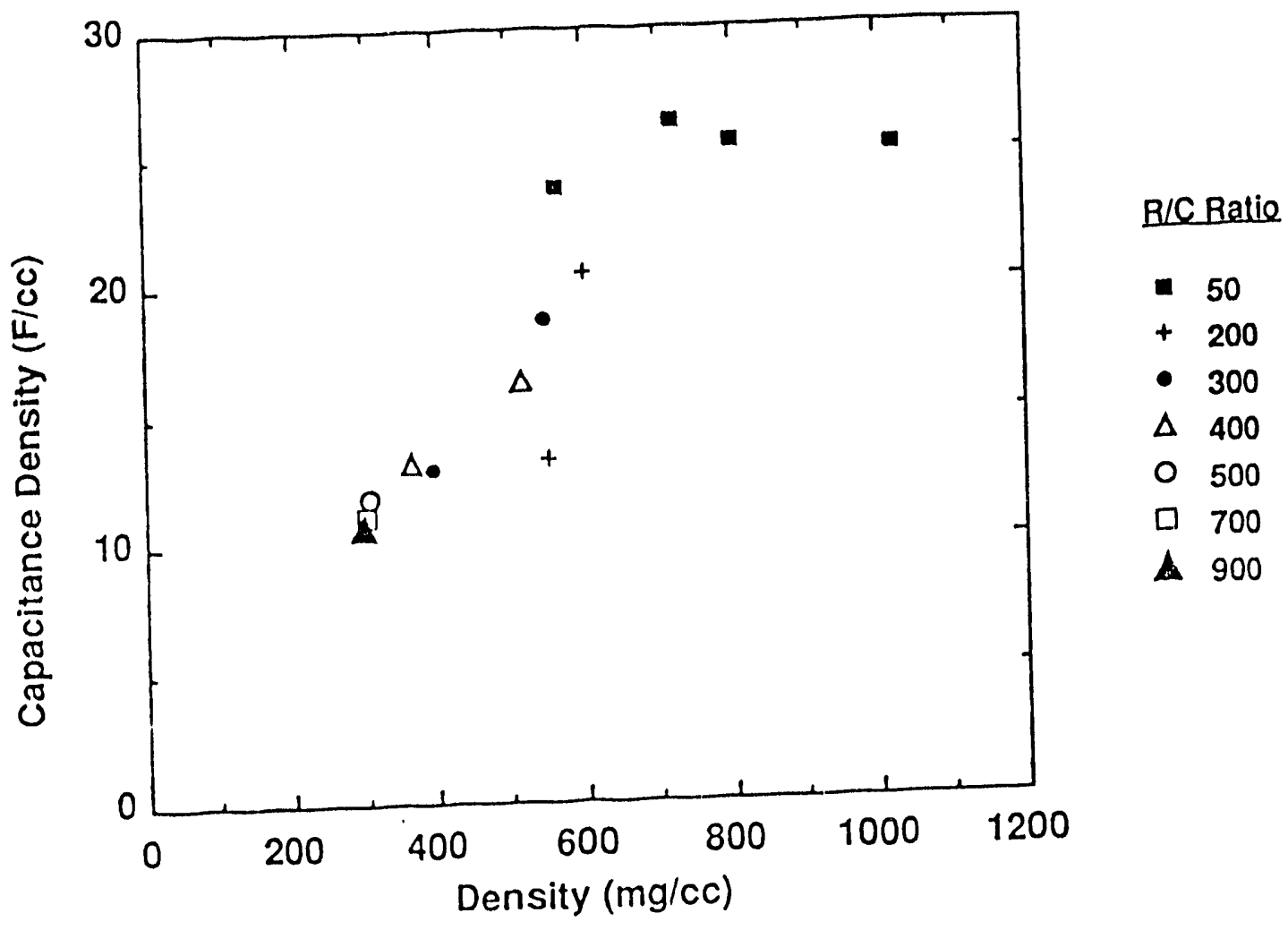

(7) 

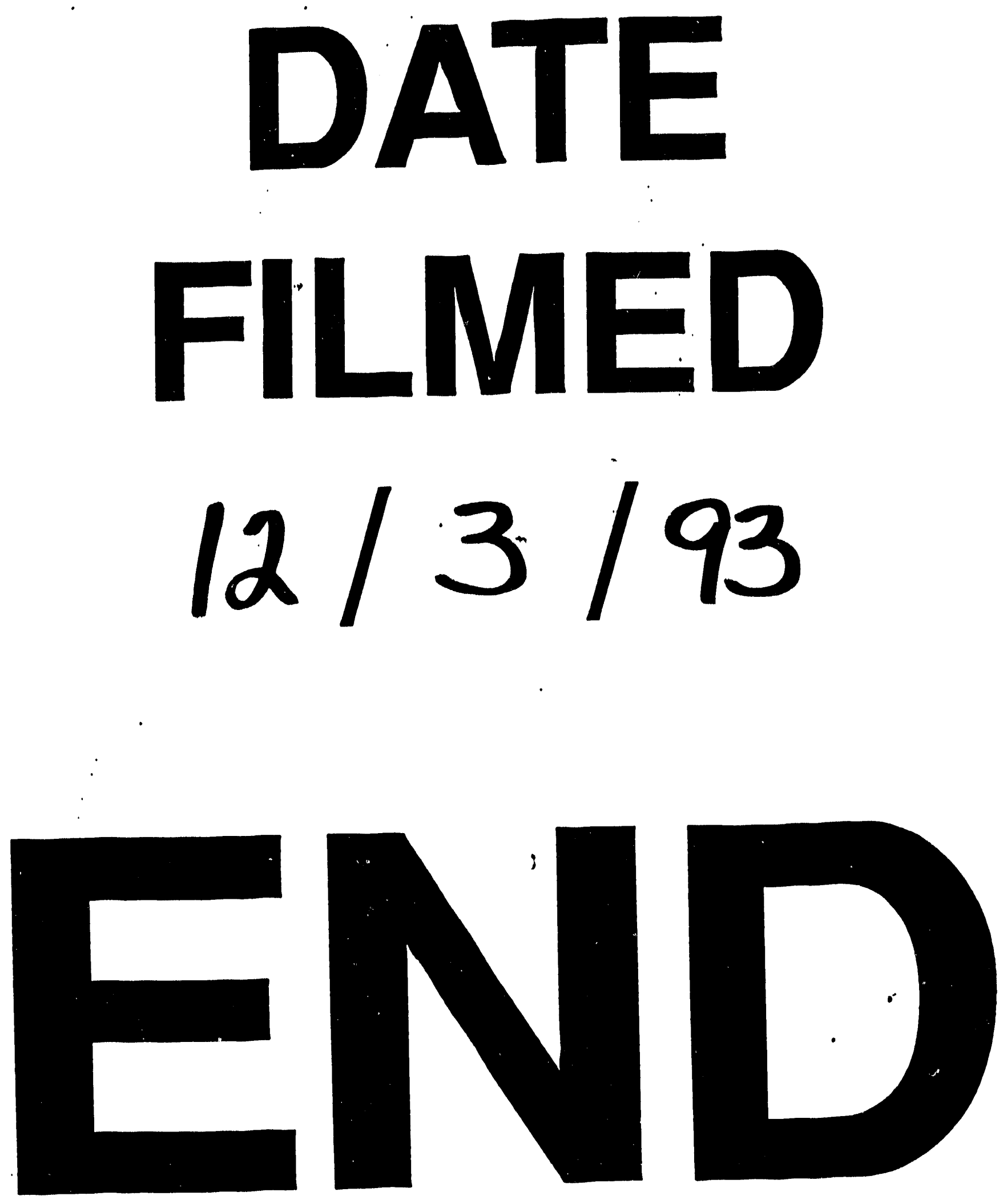


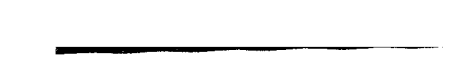

